\author{
David Gattas \\ Anders Åneman
}

\title{
The consistent inconsistency of fluid challenges in the ICU
}

\author{
We should reflect on extreme variation in our practice
}

Received: 29 June 2015

Accepted: 29 June 2015

Published online: 11 July 2015

(C) Springer-Verlag Berlin Heidelberg and ESICM 2015

D. Gattas $(\bowtie)$

Intensive Care, Royal Prince Alfred Hospital, Missenden Rd, Camperdown, Sydney, NSW 2050, Australia

e-mail: david.gattas@sydney.edu.au

D. Gattas

Sydney Medical School, University of Sydney, Sydney, NSW 2006, Australia

\section{A. Åneman}

Intensive Care Unit, Liverpool Hospital, SWSLHD, Locked Bag 7103, Liverpool BC, NSW 1871, Australia

A. Åneman

University of New South Wales, Sydney, NSW 2052, Australia

A bolus of intravenous fluid can be administered to a patient over a short period of time very easily by any clinician, and intravenous fluids are abundant and readily obtained in most hospitals. Clinicians are also motivated to deliver any treatment they think might help their patient. This helps to explain how common boluses of fluid have become: at least 1 in 3 patients in the intensive care unit (ICU) receive resuscitation fluid every day [1]. If the fluid bolus is prescribed in order to observe the effect on cardiovascular performance, or to promptly restore a perceived deficit, this is called a fluid challenge [2].

The cognitive processes that clinicians use to make individual treatment decisions for the patient in front of them are subject to powerful biases $[3,4]$. The ability of clinicians, including those who work in ICU, to accurately perceive the clinical practice which surrounds them is poor [5]. Finally, practice guidelines are drafted using methods that can also be subject to bias [6], and guidelines in intensive care medicine have made recommendations which are inconsistent with the quality of the primary evidence [7, 8]. If our clinical decisionmaking process in this area appears tangled, what does the path to progress look like?

In an article recently published in Intensive Care Medicine, Cecconi and coworkers provide welcome largescale observational data on the epidemiology of fluid challenges in the ICU. The FENICE study [9] summarises data from 2213 patients who received a fluid challenge during a 1-week period in 2013; 311 centres in 46 countries are represented, predominantly from Europe. A typical fluid challenge comprised $500 \mathrm{ml}$ of crystalloid, administered over an approximate half-hour period. Hypotension (59\% of fluid challenges) and oliguria $(18 \%)$ were the most common indications. Perhaps the most interesting finding was that responsiveness to a fluid challenge was predicted using central venous pressure (CVP) alone, or no haemodynamic variable at all in 1517 $(68.5 \%)$ patients. Finally, the administration of subsequent fluid challenges appeared to have no association with the perceived response to the first bolus of fluid.

We congratulate the authors for their assembly of a global data collection network, as well as the many others involved in the successful completion of this major project. This study is an objective, comprehensive and authoritative summary of actual fluid challenge practice. There is a great need for this type of clinical science in intensive care medicine. We do not lack sound physiologic rationales, small studies or opinions. Data such as these provide a solid foundation for evaluating if, when 
and how fluid challenges improve ICU survival or functional performance after ICU discharge.

FENICE is also significant because it argues persuasively against anyone who perceives that fluid challenges are applied consistently by themselves or by their colleagues. When the fluid challenge landscape is viewed like this from above, it is difficult to discern much pattern to our choices and actions. It appears to us that the most easily observed clinical variables (blood pressure, urine output) exert a dominant effect on clinician behaviour. The most frequently used invasive monitors (arterial lines, central venous catheters) guide most of our decisions. This occurs in spite of the poor performance of simple variables such as CVP [10] and the abundance of physiological arguments in favour of more advanced monitoring. FENICE makes it clear that we are only now just arriving at a good understanding of the epidemiology of fluid challenges in the ICU. Do the results of FENICE mean that too few patients are managed using advanced monitoring, or that we might as well be pragmatic and stop using advanced monitoring? The truth is we do not know, because we also lack any evidence which demonstrates that either approach is superior in terms of delivering longer-term, patient-centred benefits.

What we know is that this evidence is difficult (but not impossible) to collect in the intensive care environment. We cannot generalise evidence obtained from the operating theatre environment [11], where advanced monitors and therapeutic goals are used by individual anaesthetists to manage a brief patient episode. Evidence in intensive care medicine is trending away complicated and algorithm-based management of resuscitation, at least in the case of sepsis [12-14]. In the ICU, care is delivered over extended periods of time by large teams of people. Senior medical staff are only one of many decision makers regarding fluid exposure.

Does it really matter if fluid challenges are administered to patients using a panoply of indications, triggers, clinical assessments and monitoring devices? Variation is not inherently harmful, but in healthcare it deserves our attention and may be something from which we can all learn [15]. The liberal and ongoing use of fluid challenges can lead to positive fluid balance, which has been associated with harm in common ICU patient populations such as sepsis [16] and renal failure [17]. We know that minimising fluid exposure is associated with benefit in patients with lung injury [18] and abdominal surgery [19]. It seems very unlikely that this variability has anything to do with patient preference. If the truth is that there are no clinically significant differences in outcome within the broad range of typical ICU fluid practice, we still have a shared responsibility to conserve health resources and to apply them maximally only in patients we know will benefit. By facing up to the implications of FENICE, and looking forward to bigger and better intervention studies, we can discover if the way we use fluid challenges every day really matters.

Conflicts of interest The authors state that they have no financial or personal relationship with a third party whose interests could be positively or negatively influenced by the article's content and therefore have no conflict of interest.

\section{References}

1. Finfer S, Liu B, Taylor C et al (2010) Resuscitation fluid use in critically ill adults: an international cross-sectional study in 391 intensive care units. Crit Care 14:R185

2. Vincent JL, Weil MH (2006) Fluid challenge revisited. Crit Care Med 34:1333-1337

3. Croskerry P (2002) Achieving quality in clinical decision making: cognitive strategies and detection of bias. Acad Emerg Med 9:1184-1204

4. Mohan D, Angus DC (2010) Thought outside the box: intensive care unit freakonomics and decision making in the intensive care unit. Crit Care Med 38:S637-S641

5. Brunkhorst FM, Engel C, Ragaller M et al (2008) Practice and perception-a nationwide survey of therapy habits in sepsis. Crit Care Med 36:2719-2725

6. Shaneyfelt TM, Centor RM (2009) Reassessment of clinical practice guidelines: go gently into that good night. JAMA 301:868-869
7. Liu B, Finfer S (2009) Intravenous fluids in adults undergoing surgery. BMJ 338:b2418

8. Hicks P, Cooper DJ, Webb S et al (2008) The Surviving Sepsis Campaign: international guidelines for management of severe sepsis and septic shock. An assessment by the Australian and New Zealand Intensive Care Society. Anaesth Intensive Care 36:149-151

9. Cecconi M, Hofer C, Teboul JL et al (2015) Fluid challenges in intensive care: the FENICE study. Intensive Care Med. doi:10.1007/s00134-015-3850-x

10. Marik PE, Cavallazzi R (2013) Does the central venous pressure predict fluid responsiveness? An updated metaanalysis and a plea for some common sense. Crit Care Med 41:1774-1781
11. Pearse RM, Harrison DA, MacDonald $\mathrm{N}$ et al (2014) Effect of a perioperative, cardiac output-guided hemodynamic therapy algorithm on outcomes following major gastrointestinal surgery: a randomized clinical trial and systematic review. JAMA 311:2181-2190

12. The ARISE Investigators and the ANZICS Clinical Trials Group (2014) Goal-directed resuscitation for patients with early septic shock. N Engl J Med 371:1496-1506

13. Yealy DM, Kellum JA, Huang DT et al (2014) A randomized trial of protocolbased care for early septic shock. N Engl J Med 370:1683-1693

14. Mouncey PR, Osborn TM, Power GS et al (2015) Trial of early, goal-directed resuscitation for septic shock. N Engl J Med 372:1301-1311 
15. OECD (2014) Geographic variations in health care: what do we know and what can be done to improve health system performance? OECD health policy studies. OECD, Paris

16. Boyd JH, Forbes J, Nakada TA, Walley KR, Russell JA (2011) Fluid

resuscitation in septic shock: a positive fluid balance and elevated central venous pressure are associated with increased mortality. Crit Care Med 39:259-265
17. Payen D, de Pont AC, Sakr Y, Spies C, Reinhart K, Vincent JL (2008) A positive fluid balance is associated with a worse outcome in patients with acute renal failure. Crit Care 12:R74

18. Network National Heart Lung Blood Institute Acute Respiratory Distress Syndrome Clinical Trials, Wiedemann HP, Wheeler AP et al (2006)

Comparison of two fluid-management strategies in acute lung injury. New Eng J Med 354:2564-2575
19. Brandstrup B, Tonnesen H, BeierHolgersen R et al (2003) Effects of intravenous fluid restriction on postoperative complications: comparison of two perioperative fluid regimens: a randomized assessorblinded multicenter trial. Ann Surg 238:641-648 